\title{
MEDICATION ERROR OVERVIEW AND PREVENTION STRATEGIES
}

\author{
Ahmad Khan \\ MD, MS \\ A T Still Health Sciences University, USA \\ E-mail: sa205310@atsu.edu, ahmadkhan_noorzai@yahoo.com
}

\begin{abstract}
This literature review aims to highlight the overview of medication errors and strategies to avoid and decrease medication errors. Availability of various types of over-the-counter and prescribed medication has added to the risk of medication. Also, the medication chain has different steps, and different people are involved in each step, such as prescribing medication, dispensing, and administering medication. Every phase in the medication chain is prone to risks that can lead to medication errors. Medication safety is the responsibility of every healthcare professional involved in the medication chain to deliver effective and safe care to patients with an optimal outcome. A medication error can happen in every health care setting to decrease and prevent medication errors. It is critically important to have complete knowledge of the medication use chain and integrate evidence-based strategies, such as medication reconciliation, analysis of medication error, double-check, and avoiding interruption and distraction into practice. Medication errors can lead to patient harm, prevent on-time discharges, and increase care costs. Medication safety culture can shine in a setting of effectively applying strategy into practice, and everyone's collaboration and commitment to adhere to medication safety strategy can improve patient safety.
\end{abstract}

Keywords: Reconciliation, Analysis, Medication Error, Strategy.

\section{INTRODUCTION}

\section{Medication Error Overview and Prevention Strategies}

Healthcare expenses in the United States are approximately $\$ 3.5$ trillion annually. The United States of America consumes more money per person in healthcare than other developed countries (CDC, 2021). A significant portion of healthcare costs is related to medication prices. In 2016, almost $\$ 450$ billion was spent on therapeutic medication. Over time, the medication costs are presumed to increase (Aitken \& Kleinrock, 2017).

One of the primary missions of a healthcare professional is to deliver safe and effective care to the patient to reach optimal outcomes. Fostering evidence-based practices and safe use of medication is vital to high-quality and effective care (Carayon et al., 2020; Musharyanti et al., 2019). Medication errors happen in every health facility globally, and they can cause severe consequences for patients.

Error in medicine is not one hundred percent avoidable, and it constitutes a significant threat to patient safety (Bonney, 2013). One of the most prevalent medical errors that healthcare professionals and patients can encounter is medication error. It constitutes 10 to 18 percent of overall medical errors in healthcare settings (Sarhadi et al., 2015). 
A medication error can occur at any phase of the medication chain. For example, a medication error can happen during writing a prescription, dispensing, or administering the medication. Studies indicate most medication errors $(87 \%)$ happen when the medication is administered to the patient. The majority of medication errors at this step medication process are nursing related (Yousefi et al., 2014).

The financial and non-financial implications of medication error on the health system are critical. A medication error can prolong hospital stays and increase the cost of healthcare services. The financial burden of avoidable medication errors is approximately $\$ 2$ billion annually in the United States of America (Eslami, 2007).

Expansion in the variety of medications has increased the complexity of medication administration and the prescription process. There are over 10,000 types of prescription medication in 300,000 types of products available over the counter in the United States (Anderson \& Aspeden, 2007). Approximately 5\% of patients experience an adverse event from a medication side effect or an error during their stay in the hospital (Pelletier \& Beaudin, 2018).

\section{Definition}

Medication error does not have a universal definition. The concept of medication error might vary from country to country based on differing local laws. In the U.S., the National Coordinating Council for Medication Error Reporting and Prevention has defined medication error as:

"Any preventable event that may cause or lead to inappropriate medication use or patient harm while the medication is in the control of the health care professional, patient, or consumer. Such events may be related to professional practice, health care products, procedures, and systems, including prescribing, order communication, product labeling, packaging, and nomenclature, compounding, dispensing, distribution, administration, education, monitoring, and use." (NCCMERP, 2021).

\section{Medication Error Strategies}

It is essential to develop strategies to decrease the risk of medication errors in the medication delivery chains. Healthcare personnel has applied evidence-based strategies into practice to reduce and prevent the possibility of medication errors in healthcare settings.

\section{Analysis of Medication Error Events}

Reporting a medication error is a critically important asset to limit medication error instances and create strategies to prevent further medication errors (Kohn, 1999). Notwithstanding the thorough impact these errors have on the healthcare system, they extensively go under-reported, mainly due to the fear of backlash (Zhan et al., 2008).

When medication error happens, it has to be considered as a learning opportunity to improve care and reduce the chance of the same medication error in the future. When the hospital takes punitive actions against staff who make the medication error, it can lead to the demoralization of other staff to report medication errors (Pelletier \& Beaudin, 2018).

It is critically important to report medication errors to develop countermeasures in order to radically remove the occurrence of the same medication or reduce their impact. Significant causes of medication error are system-related rather than human-related factors (Rex et al., 2000). Some healthcare facilities have noticed success in enhancing the process and decreasing the medication errors via Lean Six Sigma methodology (De Koning et al., 2006). 


\section{Double Check}

Nuclear power, aviation, and other high-risk industries have a history of using double checks and triple checks to ensure that crucial processes are carried out correctly. Thankfully, most healthcare facilities now have incorporated chemotherapy and other high-risk medication (Neuss et al., 2016).

Moreover, in healthcare facilities where a double check is a requirement, it is also crucial to apply it into practice. Otherwise, it is straightforward for the second check to become lackadaisical, contributing to false reassurance in a state of genuinely increasing patient safety (Pelletier \& Beaudin, 2018).

\section{Avoiding Distractions and Interruption Factors}

Every step, in medication administration, processing, prescribing, and preparation is prone to medication errors. Even though most healthcare facilities have applied automated systems for the medication delivery steps, humans are still involved in every step of medication delivery. For example, there is a computerized system for the dosage of the medication. Still, a doctor needs to add the medication dose into the system.

Recent studies indicate that disruption and interruptions can increase the possibility of medication error in the medication delivery steps (Hayes et al., 2015). At the same time, studies indicate that reducing or removing distractions and interruption can increase medication safety (Prakash et al., 2014).

On the other hand, some argue that specific interruptions are critical to delivering highquality, effective, and safe care to the patient (Rivera-Rodriguez \& Karsh, 2010). A systematic review in 2014 showed that decreasing interruption during medication administration did not show strong evidence to support the prevention interruption and distraction strategy (Raban \& Westbrook, 2014).

\section{Medication Reconciliation}

The chance of medication error is significantly high when the patient is transitioning from one service to another service, for example, when a patient is transferred from ICU to a regular ward or a patient is transferred from a primary doctor to a specialist. Studies indicate that unintended medication inconsistency is common, happening in $30 \%$ of patients when the patient is admitted to the hospital or transferred from one service to another. Moreover, it causes moderate to severe harm in $40 \%$ of patients (Bishop et al., 2015).

Medication reconciliation is a practice to review a patient medication list on both sides of care transition in an attempt to prevent unplanned discrepancies (Rose et al., 2017).

While studies are commencing to indicate some preeminent practices in medication reconciliation, uncertainty regarding what functions still floats over, and successful studies indicate beneficial impacts on adverse drug events compared to actual patient harm (Kwan et al., 2013).

\section{CONCLUSION}

The growth of available medication has increased drug side effects and errors that threaten patient safety. Medication errors can happen at any stage of the medication chain, especially during prescription and administration steps. It is essential to assure the staff to report medication errors without punitive consequences. Reporting medication errors is the correct key to find the causes and solutions to prevent future errors. Several healthcare facilities are equipped with a computerized system that can be helpful to prevent medication errors. In addition to technology, we need to apply medication safety policies into the practice and encourage staff to stay compliant 
with the practices. Moreover, we need more research to illustrate strategies and solutions to medication errors to safely provide practical, high-quality care to the patient.

\section{ACKNOWLEDGEMENT}

I want to thank my parents for encouraging me to pursue my education at the Doctorate level. I want to thank my friends for supporting me in writing this Literature Review to help a healthcare professional. Finally, I would like to thank my wife who supported me and took care of the kids while I was working on this paper.

\section{COMPETING INTERESTS}

"There are no financial or professional competing or conflicts of interest for any of the author". Ethnical approval information:

"Ethical approval not required as this was an academic paper completed during coursework."

Data sharing statement:

No data was collected during writing the article.

\section{REFERENCES}

Aitken, M., \& Kleinrock, M. (2017). Medicines Use and Spending in the US. IQVIA Institute for Human Data Science.

Anderson, P., \& Aspden, P. (2007). Preventing medication errors (pp. 409-46). National Acad. Press.

Bishop, M. A., Cohen, B. A., Billings, L. K., \& Thomas, E. V. (2015). Reducing errors through discharge medication reconciliation by pharmacy services. American Journal of HealthSystem Pharmacy, 72(17_Supplement_2), S120-S126.

Bonney, W. (2013). Medical errors: moral and ethical considerations. J Hosp Adm, 32(32), 80-88.

Carayon, P., Wetterneck, T. B., Cartmill, R., Blosky, M. A., Brown, R., Hoonakker, P., Kim, R., Kukreja, S., Johnson, M., Paris, B., Wood, K., \& Walker, J. M. (2021). Medication safety in two intensive care units of a community teaching hospital after electronic health record implementation: sociotechnical and human factors engineering considerations. Journal of Patient Safety.

Centers for Disease Control and Prevention. (2021). Health expenditure. https://www.cdc.gov/nchs/fastats/health-expenditures.htm

De Koning, H., Verver, J. P., van den Heuvel, J., Bisgaard, S., \& Does, R. J. (2006). Lean six sigma in healthcare. Journal for Healthcare Quality, 28(2), 4-11.

Eslami, S., Abu-Hanna, A., \& De Keizer, N. F. (2007). Evaluation of outpatient computerized physician medication order entry systems: a systematic review. Journal of the American Medical Informatics Association, 14(4), 400-406. 
Hayes, C., Jackson, D., Davidson, P. M., \& Power, T. (2015). Medication errors in hospitals: a literature review of disruptions to nursing practice during medication administration. Journal of clinical nursing, 24(21-22), 3063-3076.

Kwan, J. L., Lo, L., Sampson, M., \& Shojania, K. G. (2013). Medication reconciliation during transitions of care as a patient safety strategy: a systematic review. Annals of internal medicine, 158(5_Part_2), 397-403.

Kohn, L. T. (1999). Errors in health care: a leading cause of death and injury In: Kohn LT, Corrigan JM, Donaldson MS.

Musharyanti, L., Claramita, M., Haryanti, F., \& Dwiprahasto, I. (2019). Why do nursing students make medication errors? A qualitative study in Indonesia. Journal of Taibah University Medical Sciences, 14(3), 282-288.

National Coordination Council for Medication Error Reporting and Prevention. (2021). About medication errors: What is a medication error? Retrieved from https://www.nccmerp.org/about-medication-errors.

Neuss, M. N., Gilmore, T. R., Belderson, K. M., Billett, A. L., Conti-Kalchik, T., Harvey, B. E., Lefebvre, K. B., Mangu, P. B., McNiff, K., Oslen, M., Schulmeister, L., Gehr, A., \& Polovich, M. (2016). 2016 updated American Society of Clinical Oncology/Oncology Nursing Society chemotherapy administration safety standards, including standards for pediatric oncology. Journal of oncology practice, 12(12), 1262-1271.

Pelletier, L. \& Beaudin, C. (Eds.). (2018). Health quality solutions. National Association for Health care Quality.

Prakash, V., Koczmara, C., Savage, P., Trip, K., Stewart, J., McCurdie, T., Cafazzo, J. A., \& Trbovich, P. (2014). Mitigating errors caused by interruptions during medication verification and administration: interventions in a simulated ambulatory chemotherapy setting. BMJ quality \& safety, 23(11), 884-892.

Raban, M. Z., \& Westbrook, J. I. (2014). Are interventions to reduce interruptions and errors during medication administration effective?: a systematic review. BMJ quality \& safety, 23(5), 414-421.

Rex, J. H., Turnbull, J. E., Allen, S. J., Voorde, K. V., \& Luther, K. (2000). Systematic root cause analysis of adverse drug events in a tertiary referral hospital. The Joint Commission journal on quality improvement, 26(10), 563-575.

Rivera-Rodriguez, A. J., \& Karsh, B. T. (2010). Interruptions and distractions in healthcare: review and reappraisal. BMJ Quality \& Safety, 19(4), 304-312.

Rose, A. J., Fischer, S. H., \& Paasche-Orlow, M. K. (2017). Beyond medication reconciliation: the correct medication list. Jama, 317(20), 2057-2058. 
Sarhadi, M., Abdollhyar, A., Navidian, A., Sheikh Bardsiri, H., \& Sarhadi, T. (2015). The investment of effective factors on medical errors and non-reporting from nurse's perspective. Journal of Sabzevar University of Medical Sciences, 22(1), 132-142.

Yousefi, M. S., Abed Saeedi, Z., Maleki, M., \& Sarbakhsh, P. (2014). Frequency and causes of medication errors of nurses in different shift works in educational hospitals affiliated to Shahid Beheshti University of Medical Sciences.J Shahid Beheshti Sch Nurs Midwifery, 24(24), 27-34.

Zhan, C., Smith, S. R., Keyes, M. A., Hicks, R. W., Cousins, D. D., \& Clancy, C. M. (2008). How useful are voluntary medication error reports? The case of warfarin-related medication errors. The Joint Commission Journal on Quality and Patient Safety, 34(1), 36-45.

\section{Copyrights}

Copyright for this article is retained by the author(s), with first publication rights granted to the journal. This is an open-access article distributed under the terms and conditions of the Creative Commons Attribution license (http://creativecommons.org/licenses/by/4.0) 